\title{
The gas flow dynamics in a separator with coaxially arranged pipes
}

\author{
Vadim E. Zinurov ${ }^{1, *}$, Andrey V. Dmitriev ${ }^{1}$, Guzel R. Badretdinova ${ }^{1}$, Rustem Ya. Bikkulov ${ }^{1}$ \\ and Ilnur N. Madyshev ${ }^{2}$ \\ ${ }^{1}$ Kazan State Power Engineering University, 420066, Kazan, Krasnoselskaya str., 51, Russia \\ ${ }^{2}$ Kazan National Research Technological University, 420015, Kazan, Karl Marx str., 68, Russia
}

\begin{abstract}
In order to increase the efficiency of gas purification from the particles of up to 20 microns and to increase the service life of bag and electrostatic filters, the authors propose to use a centrifugal separation device with coaxially arranged pipes to be installed before the fine purification devices. The numerical studies of gas dynamics in a separation device were conducted in ANSYS Fluent software package. As a result of conducted numerical studies, it was found that the pressure loss in the centrifugal separation device is not more than $70 \mathrm{~Pa}$ at the inlet gas flow rate from 1 to $15 \mathrm{~m} / \mathrm{s}$ and the width of rectangular hole within the range from 10 to $15 \mathrm{~mm}$. The low pressure losses are caused by the design features; in particular, the resulting vortices in the inter-cylindrical space practically do not contact the wall surfaces of device. The equations of pressure loss depending on the width of rectangular holes and the hydraulic resistance coefficient of separation device depending on the inlet gas flow rate were obtained. The design coefficient of hydraulic resistance of separation device was equal to 0.45 .
\end{abstract}

\section{Introduction}

Nowadays, much attention is paid to the problem of improving the efficiency of purifying the gas flows from the finely dispersed particles less than 10-20 microns. This problem is relevant for the enterprises of all industrial fields: agricultural, electric-power, metallurgical, petrochemical, etc. Uncollected during the purification process, the finely dispersed particles at the industrial enterprises cause the failure of devices due to clogging with various type of dirt, formed by the accumulation of dust [1-4]. Also, uncollected finely dispersed particles often cause a decrease in the properties of devices, an increase in the hydraulic resistance of pipelines and lead to explosive and fire-hazardous situations [5-9]. For example, at the gas distribution stations, the finely dispersed particles, when getting into the process and gas-regulating equipment, impair operation of them. In some cases, the finely dispersed particles are a valuable material that can be reused in various processes and for the production of various products. For example, the collected ash particles at thermal power plants are widely used in the construction industry. When adding the collected ash to

*Corresponding author: vadd_93@mail.ru 
the building materials, their strength increases, which leads to an improvement of performance properties and allows for an economic effect [10-15].

In order to solve the problem of purifying the gas flows from the finely dispersed particles, there are a large number of different devices that differ significantly from each other in design and principle of operation. However, at the current time, a universal device that meets all the technological requirements has not been developed yet. Each of the devices has a number of positive properties and disadvantages. Among all the devices, the most widely used are the cyclone separators, related to dry purification. The simple operating principle i.e. the gas flow purification from the dust particles is carried out by knocking out the particles from the flow structure, when it becomes a vortex in the cylindrical part of device; as well as simplicity of design, durability and high efficiency of purifying the gas flows from the dust particles larger than 20 microns. The disadvantages of cyclone separators are the following: low efficiency of gas purification from the particles less than 20 microns and high hydraulic resistance. As a rule, in order to increase the purification efficiency from the particles smaller than 20 microns, the diameter of cylindrical part of device is reduced, which increases the values of centrifugal forces, as well as several cyclone separators are used, which are installed in parallel, forming the battery cyclones. The installation of such devices is often complicated by the production conditions: a large production area is required and maintenance requirements are increased as well. Therefore, if it is necessary to purify the gases from the finely dispersed particles, a second stage of purification, i.e. bag or electrostatic filters, shall be installed after the cyclone separators. These devices allow further purification of gas flows from the particles of up to 20 microns with efficiency close to $100 \%$. However, bag filters and electrostatic filters need periodic maintenance, such as: cleaning, replacement of filter elements, etc. With a high degree of contamination, the hydraulic resistance of them increases and the purification efficiency decreases. It should be noted that the cost of consumables for these devices is quite high. Therefore, the task of improving the efficiency of purifying the gas flows from the finely dispersed particles of up to 20 microns is quite relevant.

\section{The description of developed centrifugal separation device}

The authors developed a design of centrifugal separation device with coaxially arranged pipes (figure 1), which is proposed to be used for purifying the gas flows from the finely dispersed particles of up to 20 microns, installing it after the first stage and before the second stage of purification, i.e. before a bag or electrostatic filter, which also increases their service life.

The separation device is a cylindrical body 3, inside which there is an internal cylindrical pipe with rectangular holes 4 . In the upper part of separation device there is a central round hole 1 , which works as an inlet nozzle. In the direction to the periphery from the inlet nozzle, there is an axisymmetric row of round holes that form the outlet nozzles from the separation device. It should be noted that the advantage of the developed separation device is an ease of manufacture, since the main structural elements are internal and external cylindrical pipes, which can be chosen according to GOST. Thus, this device is possible to be manufactured in the fitting workshop of enterprise.

The operating principle of separation device can be described as follows: a dusty gas flow with the finely dispersed particles of up to 20 microns enters the device through the inlet nozzle 1 , then moves downwards along the normal relative to the bottom of separation device; as the flow reaches the areas that are parallel to the rectangular holes, it begins evenly distribute itself over them. It should be noted that when the dusty gas flow is distributed through the rectangular holes, it gradually changes its movement direction that contributes to the loss of dust particles larger than 20 microns from the flow, which were 
not collected at the first stage of purification. Further, each jet of dusty gas flow at the exit from the rectangular holes is divided into two parts, which move in opposite directions relative to each other, forming vortices. A special feature of separation device is that each vortex, during its rotation, has points of contact with neighboring vortices. When neighboring vortices are in contact, additional mutual acceleration is performed. When rotating, the gas flow rises through the inter-cylindrical space to the upper part of device and exits the separation device through the outlet holes 2 . It should be noted that during the rotation of gas flow in the inter-cylindrical space of device, centrifugal forces of large values appear that contributes to the separation of finely dispersed dust particles from the dusty flow. When being knocked out the gas flow, the particles fall into the stagnant zones and settle to the bottom of device or stick to the wall surfaces. As can be seen from the description of operating principle of separation device, the main role is played by the formation of stable vortex structure in the inter-cylindrical space. Therefore, the purpose of this study is to simulate the gas dynamics in a separation device with a numerical method.

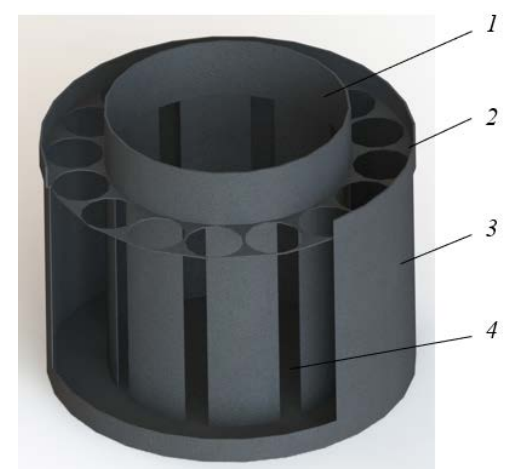

Fig. 1. A three-dimensional model of centrifugal separation device with coaxially arranged pipes (cross-section view): 1 - inlet nozzle of inner cylindrical pipe, 2 - grid with round holes, 3 - body of separation device, 4 - rectangular holes.

The numerical simulation was conducted by means of ANSYS Fluent software package. It should be noted that this software product is used for calculating complex flows of liquids and gases with the possibility of varying the thermophysical parameters of medium. The program uses the finite element method, which is a grid method. The flow of liquids and gases is calculated by solving the Navier-Stokes equation:

$$
\frac{\partial \overrightarrow{\boldsymbol{v}}}{\partial t}=-(\overrightarrow{\boldsymbol{v}} \cdot \nabla) \overrightarrow{\boldsymbol{v}}+v \Delta \overrightarrow{\boldsymbol{v}}-\frac{1}{\rho} \nabla p+\overrightarrow{\boldsymbol{f}}
$$

where $\nabla$ - nabla; $\Delta$ - vector Laplace operator; $t$ - time period, $\mathrm{s} ; v$ - kinematic viscosity coefficient, $\mathrm{m}^{2} / \mathrm{s} ; \rho$ - density, $\mathrm{kg} / \mathrm{m}^{3} ; p$ - pressure, $\mathrm{Pa} ; \overrightarrow{\boldsymbol{v}}$ - velocity vector field; $\overrightarrow{\boldsymbol{f}}-$ vector field of mass forces.

The Navier-Stokes equation is supplemented with the continuity equation:

$$
\frac{\partial \rho}{\partial t}+\nabla \cdot(\rho \overrightarrow{\boldsymbol{v}})=0
$$

Transition SST, which is an improved standard SST model, was used as the turbulence model. In contrast to the standard model, two additional transfer equations are added to Transition SST: 1) for intermittency, 2) for the high-speed head, which is calculated for the thickness of momentum loss. 
In order to conduct the numerical calculations, a three-dimensional model of centrifugal separation device, with coaxially arranged pipes and the following dimensions, was created: height and diameter of inner cylindrical pipe - 125 and $100 \mathrm{~mm}$, respectively; diameter of holes within the grid $-24 \mathrm{~mm}$; height of hole $-97 \mathrm{~mm}$; height and diameter of outer cylindrical pipe -100 and $130 \mathrm{~mm}$, respectively (figure 1).

In the course of numerical simulation, the inlet rate $w, \mathrm{~m} / \mathrm{s}$, which varied from 1 to 15 , was set at the inlet nozzle of centrifugal separation device with coaxially arranged pipes. The width of rectangular holes b also changed from 10 to $15 \mathrm{~mm}$. At the outlet nozzle 2, a pressure of $101325 \mathrm{~Pa}$, equal to atmospheric value, was set, and the air density $\mathrm{p}$ was set as equal to $1.2 \mathrm{~kg} / \mathrm{m}^{3}$.

In the course of study, the pressure loss $\Delta p$ in a centrifugal separation device with coaxially arranged pipes was calculated as follows:

$$
\Delta p=p_{1}-p_{2},
$$

where $p_{1}$ - pressure at the inlet nozzle 1 of separation device, $\mathrm{Pa} ; p_{2}$ - pressure at the outlet nozzle 2 of separation device, Pa.

The hydraulic resistance coefficient $\zeta$ was calculated according to the formula:

$$
\zeta=\frac{2 \Delta p}{\rho w^{2}}
$$

where $w$ - velocity, $\mathrm{m} / \mathrm{s}$.

\section{The results of study and description of them}

In the course of numerical studies, it was found that the pressure loss in the centrifugal separation device is not more than $70 \mathrm{~Pa}$ at the inlet gas flow rate from 1 to $15 \mathrm{~m} / \mathrm{s}$ and the width of rectangular hole within the range from 10 to $15 \mathrm{~mm}$. The low pressure losses are explained by the design simplicity; in particular, the resulting vortices in the intercylindrical space practically do not contact the wall surfaces. This allows minimizing the gas flow slowdown, i.e. to minimize the pressure loss caused by friction. When changing the width of hole and the inlet gas flow rate, the vortex flow structure in the intercylindrical space of centrifugal separator with coaxially arranged pipes significantly changes. The most stable vortex structure was observed at the inlet gas flow rate and the width of hole $-10 \mathrm{~m} / \mathrm{s}$ and $12 \mathrm{~mm}$, respectively. It was also found that the rate is unevenly distributed in rectangular holes along the height. This is due to the fact that when the gas flow moves from the inlet nozzle to the lower part of device, the flow first moves to the nearby area, which turns out to be the upper part of rectangular holes. As a result, the radial rate of gas flow is higher in the upper parts of rectangular holes than in the lower ones.

Figure 2 shows the gas flow movement in a centrifugal separation device with coaxially arranged pipes at different inlet rates and widths of holes. As can be seen, a stable structure of vortices in the inter-cylindrical space is formed only at certain values of technological and structural parameters, which also correlate with each other. When the width of rectangular hole is equal to $12 \mathrm{~mm}$, a fairly stable vortex structure is formed, which also traces the height of device (figures 2-1.a and 1.b). When the rectangular holes are reduced to $7 \mathrm{~mm}$, the vortices destroy each other. This does not allow creating a stable vortex structure in the inter-cylindrical space (figures 2-2.a and 2.b). In order to stabilize the vortex structure in the inter-cylindrical space, it is necessary to reduce the diameter of outer cylindrical pipe, since it is clearly seen in figure 2-2. that there is a large area of discharge between the vortices, which negatively affects the rotation of them. 

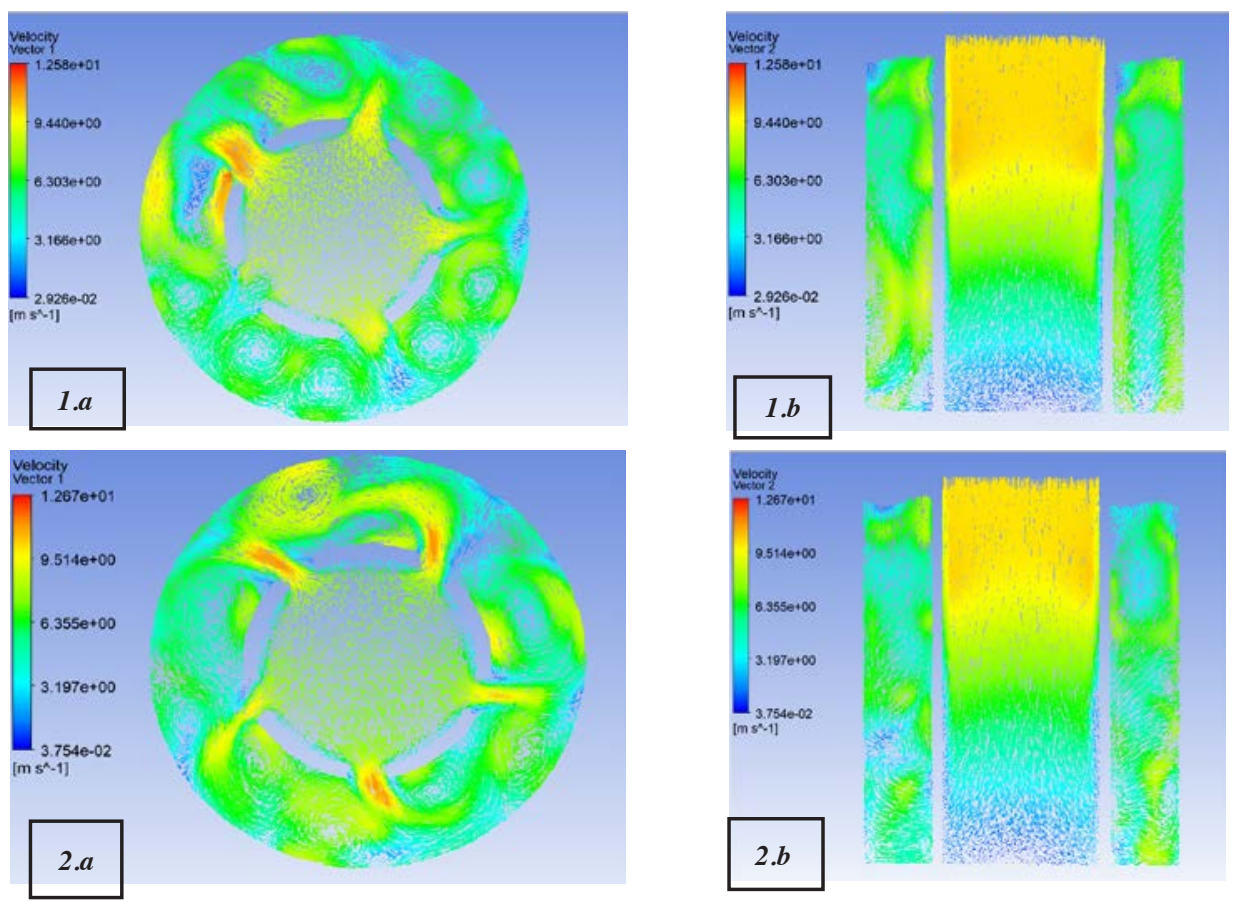

Fig. 2. The visualization of gas dynamics in a centrifugal separation device with coaxially arranged pipes in different cross sections: 1 - inlet gas rate $-10 \mathrm{M} / \mathrm{c}$, width of hole $-12 \mathrm{~mm}, 2$ - inlet gas rate$10 \mathrm{~m} / \mathrm{s}$, width of hole $-7 \mathrm{~mm}$ ( $a$ - top view, $b$ - side view).

The pressure loss in a centrifugal separation device with coaxially arranged pipes on average is equal to $32 \mathrm{~Pa}$ at the inlet gas flow rate of $10 \mathrm{~m} / \mathrm{s}$ and the width of hole of 10 to $15 \mathrm{~mm}$. As the width of hole increases, the pressure loss in the separation device changes according to the obtained dependence (5). The pressure loss in the device on average is reduced by $9 \%$ when the width of hole is reduced by $1.6 \mathrm{~mm}$ (figure 3 ). This change in the pressure loss is explained by the fact that with wider holes, it is easier for the gas flow to be distributed over them when it moves to the lower part of separation device from the inlet nozzle 1 (figure 1).

$$
\Delta p=-1.75 b+54.2
$$

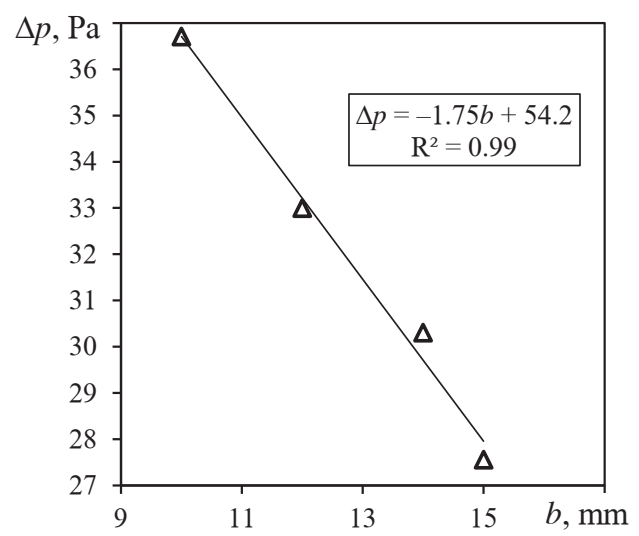

Fig. 3. The dependence of pressure loss in a centrifugal separation device with coaxially arranged pipes on the width of hole. The inlet gas flow rate is $10 \mathrm{~m} / \mathrm{s}$. 
The hydraulic resistance coefficient of centrifugal separation device with coaxially arranged pipes is on average equal to 0.45 , when the inlet gas flow rate changes from 1 to $15 \mathrm{~m} / \mathrm{s}$. At the same time, the width of rectangular hole was equal to $15 \mathrm{~mm}$. The maximum error in determining the hydraulic resistance coefficient was not more than $9 \%$ (figure 4 ). The equation of dependence of hydraulic resistance coefficient of device on the inlet gas flow rate (6) was obtained as well.

$$
\zeta=0.004 w+0.42 .
$$

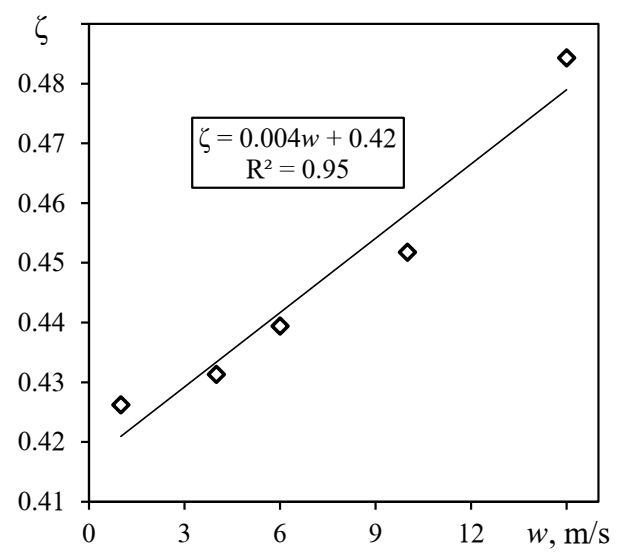

Fig. 4. The dependence of change in the hydraulic resistance coefficient $\zeta$ on the inlet gas flow rate $w$. The width of rectangular hole $b=15 \mathrm{~mm}$.

Thus, the numerical studies showed that changes in the technological parameters, in particular, the inlet gas flow rate and structural parameters, in particular, the width of hole, significantly affect the creation of vortex flow structure in the inter-cylindrical space.

\section{Conclusion}

This scientific article deals with the developed centrifugal separation device with coaxially arranged pipes for purifying the gas flows from the finely dispersed particles of up to 20 microns. The conducted numerical studies showed that the device is advantageous from an energy point of view, since low pressure losses of up to $70 \mathrm{~Pa}$ are achieved in it the inlet gas flow rate from 1 to $15 \mathrm{~m} / \mathrm{s}$. The low pressure losses are caused by the design features; in particular, the resulting vortices in the inter-cylindrical space practically do not contact the wall surfaces of device. The equations of pressure loss depending on the width of rectangular holes (5) and the hydraulic resistance coefficient of separation device depending on the inlet gas flow rate (6) were obtained. The design coefficient of hydraulic resistance of separation device was on average equal to 0.45 . It was found that the most stable vortex structure in the inter-cylindrical space of centrifugal separation device is achieved when the width of holes is equal to $12 \mathrm{~mm}$ and the inlet gas flow rate is equal to $10 \mathrm{~m} / \mathrm{s}$, since with these parameters, the formed vortices have the most effective radius, at which the distance between the vortices is minimal, allowing neighboring vortices additionally to unwind each other. In this case, the vortices do not overlap each other and there are no discharge zones between them.

It should be noted that the developed device creates a large number of vortices in the inter-cylindrical space with the values of centrifugal forces ten times higher than the cyclone separators create, since the radius of vortices is ten times less than the radius of cylindrical body in the cyclone separator. Due to higher values of centrifugal forces, the gas 
flows are purified from the finely dispersed particles of up to 20 microns in the separation device with coaxially arranged pipes.

The advantages of the developed centrifugal separation device with coaxially arranged pipes are the following: design simplicity, high efficiency, low pressure losses in the device, low operating and capital costs.

The study was supported by the grant of the President of the Russian Federation No. MK-616.2020.8.

\section{References}

1. S. Altmeyer, V. Mathieu, S. Jullemier, P. Contal, N. Midoux, S. Rode, J.P. Leclers, Chem. Eng. Prog, 43, 511-522 (2004)

2. P. Baltrenas, M. Pranskevicius, A. Venslovas, Energy Procedia, 72, 188-195 (2015)

3. A.V. Dmitriev, V.E. Zinurov, O.S. Dmitrieva, Matec Web of Conferences, 224, 02073 (2018)

4. A.V. Dmitriev, V.E. Zinurov, O.S. Dmitrieva, E3S Web of Conferences, 126, 00007 (2019)

5. S.M. Clifford, J. Zhang, T. Sigsgaard, M. Jantunen, P.J. Lioy, R. Samson, M.H. Karol, Environ. Health Perspect., 115, 958-964 (2007)

6. F. Shuanshi, X. Wang, X. Lang, Y. Wang, Nat. Gas Ind., 4(6), 470-476 (2017)

7. B. Sagot, A. Forthomme, L. Ait Ali Yahia, G. De La Bourdonnaye, J. Aerosol Sci., 110, 53-69 (2017)

8. A.V. Dmitriev, V.E. Zinurov, O.S. Dmitrieva, IOP Conf. Ser.: Materials Sci. and Eng., 451(1), 012211 (2018)

9. V.E. Zinurov, O.S. Popkova, V.L. Nguyen, E3S Web of Conferences, 126, 00043 (2019)

10. S. Bernardo, M. Mori, A.P. Peres, R.P. Dionisio, Powder Technol., 162, 190-200 (2006)

11. N.A. Merentsov, V.A. Balashov, S.A. Bokhan, E.E. Nefed'eva, D.A. Tezikov, V.V. Groshev, IOP Conf. Ser.: Earth Environ. Sci., 224, 012041 (2019)

12. J. Chang, P. Wang, L. Cui, Z. Li, C. Ma, X. Wang, J. Electrost., 95, 53-60 (2018)

13. B.K. Lee, K.R. Jung, S.H. Park, J. Aerosol Sci., 12, 1079-1088 (2008)

14. Y. Su, A. Zheng, B. Zhao, Powder Technol., 210, 293-303 (2011)

15. R. Singh, A. Shukla, Renewable Sustainable Energy Rev., 40, 118-132 (2014) 